\title{
Sero-Prevalence of Anti HCV Among Blood Donors Attended at Transfusion Medicine Department of DMCH in 2013
}

\author{
*S Karim ${ }^{1}$, E Hoque $^{2}$, HA Begum $^{3}$, MM Hoque $^{4}$ \\ $1 *$ Dr. Shanaz Karim, Assistant Professor, Department of Transfusion Medicine, Dhaka Medical College Hospital \\ ${ }^{2}$ Dr. Ehteshamul Hoque, Professor, Department of Oncology, Anwer Khan Modern Medical College \\ ${ }^{3}$ Dr. Hussne Ara Begum, Professor and Head of Department of Transfusion Medicine, Dhaka Medical College Hospital \\ ${ }^{4}$ Dr Mazharul Hoque , Associat Professor, Department of Transfusion Medicine, Dhaka Medical College Hospital \\ *Corresponding Author
}

\begin{abstract}
Bacground: Post transfusion hepatitis through blood and blood product is still very high in our country. This present study was carried out to find out the prevalence of sero Positive of anti $\mathrm{HCV}$ among the blood donors attended at transfusion medicine department of DMCH in 2013 and also to prevent transmission of HCV infection through blood transfusion.
\end{abstract}

Methodology: This cross sectional study was carried out at transfusion medicine department of DMCH from 1st January 2013 to 31st December 2013.Total blood donors were 27,560. Among total 31890 blood donors, relative donors were 25,773. and remaining 6,117 donors were voluntary donors. Blood donors of 18 - 60 years of both sexes were included in this study. Among 31,890 blood donors relative blood donors were $25,773(80.81 \%)$, voluntary blood donors were 6,117.(19.18\%)Among 31,890 blood donors Anti HCV Sero positive were 33(0.1034\%).

Result: Among total blood donors male and female were 25,880 ( $81.15 \%)$ and 6010 (18.85\%) respectively. Age ranges of donors were $18-40$ years $28500(86.23 \%)$ and $41-60$ years $3390(10.63 \%)$.

Conclusion: Frequency of HCV seropositive among donors were $33(.1034 \%)$.

Key Words: HCV, Blood donors, Seropositive

\section{Introduction}

Transmission of infectious diseases through donated blood is of concern in order to provide safe blood for transfusion which forms an integral part of medical and surgical therapy. Blood transfusion carries the risk of transfusion induced transmissible infections including HIV, hepatitis, syphilis, malaria and less frequently toxoplasmosis, brucellosis and some viral infections like EpsteinBarr virus, cytomegalovirus and herpes ${ }^{1}$. Hepatitis $\mathrm{C}$ virus (HCV) infection is an important global health problem and may cause acute and chronic infection in man and is one of the most common causes of chronic liver disease, cirrhosis of liver and hepatocellular carcinoma. HCV accounts for $40 \%$ of chronic liver disease ${ }^{2}$. It is estimated that about $3 \%$ of global population is infected with $\mathrm{HCV}$ although prevalence ranges from 0.1 to more than $12 \%$, depending on country which equals to approximately 170 million chronic carriers worldwide ${ }^{3}$. The first reports of hepatitis following a blood transfusion occurred in $1943^{4}$.

AKMMC J 2015; 6(1): 25-27

\section{Methodology}

This study was carried out on 31,890 blood donors in Department of Transfusion Medicine Dhaka Medical College Hospital .Dhaka from 1st January 2013 to 31st December 2013. Among the 31,890 blood donors who attended at Transfusion Medicine Department at $\mathrm{DMCH}, 25,773$ were relative donors and remaining 6117 were voluntary donors The age distribution of donor was $18-60$ years. Blood donors were selected after proper history taking and physical examination of donor which includes pulse, blood pressure, weight and $\mathrm{Hb} \%$.Prepared questionnaire in national language were used for selection of donor. Those who were illiterate assisted by donor registration stuff. Consent obtained in writing form from the donor after explaining the procedure, potential adverse reactions as well as the tests carried out on the donated blood .Some donors were rejected by self exclusion during conversation. Finally reviewed donor's health condition and performing physical examination / $\mathrm{Hb}$ estimation with scala matching method by principal author. After fulfilling the criteria of donor selection with all aseptic precaution $5 \mathrm{ml}$ of blood was collected in prelabeled pilot tube. Centrifuged the 
Sero-Prevalence of Anti Hcv Among Blood Donors Attended

blood and separated the serum from cell. Detection of Anti-HCV antibody was done by Latex agglutination immuno chromatographic test with the instruction of reagent manufacture. The tests were reconfirmed by using ELISA method.

\section{Results}

The data was collected from the registered of Transfusion Medicine Department of DMCH. In this study among 31,890 blood donors, relative blood donors were $25,773(80.81 \%)$ and voluntary blood donors were 6117.(19.18\%) Among total blood donors male and female were $25,880(81.15 \%$ )and $6010(18.85 \%)$ respectively. Age ranges of donors were 18 -40 years $28500(86.23 \%)$ and 41-60 years $3390(10.63 \%)$ Frequency of $\mathrm{HCV}$ seropositive among donors were $33(.1034 \%)$.

Results are showing in following tables.

Table-I: Distribution of types of blood donors (n31890),

\begin{tabular}{ccc}
\hline Types of donor & Number & $\%$ \\
\hline Relative & 25773 & 80.81 \\
Voluntary & 6117 & 19.18 \\
\hline
\end{tabular}

Table-II: Distribution of age of blood donors (n31890)

\begin{tabular}{ccc}
\hline Age & Number & $\%$ \\
\hline $18-40$ Year & 28500 & $86.23 \%$ \\
41 -60 Year & 3390 & $10.63 \%$ \\
\hline
\end{tabular}

Table-III: Distribution of sex of blood donor (n-31890)

\begin{tabular}{lll}
\hline Sex & Number & $\%$ \\
\hline Male & 25880 & $81.15 \%$ \\
Female & 6010 & $18.84 \%$ \\
\hline
\end{tabular}

Table-IV: Frequency of HCV Sero positive (n-31890)

\begin{tabular}{lcc}
\hline Total Donor & Number of anti HCV seropositive & \% \\
\hline 31890 & 33 & $.1034 \%$ \\
\hline
\end{tabular}

\section{Discussion}

In Transfusion Medicine Department of Dhaka Medical College Hospital, no professional blood donor had taken part in donation programmed . But the number of voluntary donor was also poor. In one study done by Safe Blood Transfusion Center, $\mathrm{HCV}$ positive $(0.15 \%),{ }^{5}$. Study in $\mathrm{KMCH}, \mathrm{HCV}$ positive $(0.024 \%),{ }^{6}$. In a study in Canada, , HCV positive $(16.83 \%)^{7}$. Indian studies indicate that seroprevalence of $\mathrm{HCV}$ ranges between 0.4-1. $09 . \% 8$.

In this study among 31890 blood donors, relative blood donors were $25773((80.81 \%)$ and voluntary blood donors were 6117. (19.18\%) Among total blood donors male and female were 25880 ( $81.15 \%$ )and 6010 (18.84\%) respectively. Age ranges of donors were $18-40$ years $28500(86.23 \%)$ and 41-60 years $3390(10.63 \%)$ Frequency of HCV seropositive among donors were 33 (.1034 \%) Different Asian countries had reported seropositivity in blood donors. Prevalence of HCV in North Pakistan was $2.46 \%{ }^{9}$. Central Saudi Arabia had reported $.4 \%, \mathrm{HCV}^{10}$. In Bangladesh, $0.024 \%$ were positive for anti-HCV ${ }^{11}$. In Kathmandu, Nepal, seroprevalence of $\mathrm{HCV}$ was observed to be $0.64 \% 12$. Low prevalence rate in our study due to proper donor selection, blood screening and public awareness about HCV infection.

\section{Conclusion}

Post transfusion hepatitis will be significantly reduced through proper donor selection and screening of donated blood. HCV sero positive donors should be informed about their disease, counseled and sent for confirmation to referral laboratory. After confirmation seropositive donor should referred to hepatologist for proper management. Save the patient as well as donor.

\section{Reference}

1. Arora D, Arora B, Khetarpal A. Seroprevalence of HIV, HBV, HCV and syphilis in blood donors in Southern Haryana. Indian $\mathrm{J}$ Pathol Microbial 2010;53(2): 308-9. 
AKMMC J $2015: 6(1)$

2. Center for Disease Control. Recommendation for prevention and control of HCV infection and HCV related disease. MMWR Marly Morty Weekly Report 1998; 47: 1-40.

3. Global surveillance and control of hepatitis C. Reports of a WHO Consultation organized in collaboration 3 with the Viral Hepatitis Prevention Board, Antwerp, Belgium. J Viral Hepatol. 1999; 6: 35-47.

4. Beeson PB. Jaundice occurring one to four months after transfusion of blood or plasma. Report of seven cases. JAMA 1943; 121: 13321334.]

5. Safe Blood Transfusion Center. Annual reports of donor screening, DMCH, Dhaka. 2009.

6. Ahmed MU, Begum HA, Hossain T, Incidence of common transfusion transmitted disease among blood donors. JAFMC, Bangladesh. 2009; 5(1):

7. Chiavetta JA, Escobar M, et al. Incidence of HBV, HCV and HIV in Canada, CMAJ. 2003; 169(8):

8. Ahmed MV, Begum HA, Hossain T, Chakraborty $\mathrm{P}$. Incidence of common transfusion transmitted diseases among blood donors. JAFMC Bangladesh 2009; 5(1): 4-6.
S Karim, E Hoque, HA Begum et al

9. Asif N, Khokhar N, Ilahi F. Seroprevalence of HBV, HCV and HIV infection among voluntary non remunerated and replacement donors in Northern Pakistan. Pak J Med Sci 2004;20:24-8.

10 El-Hazmi MM. Prevalence of HBV, HCV, HIV1, 2 and HTLV-I/II infections among blood donors in a teaching hospital in the Central region of Saudi Arabia. Saudi Med J 2004; 25: 26-33.

11 Ahmed MU, Begum HA, Hossain T, Chakraborty P. Incidence of Common Transfusion Transmitted Diseases Among Blood Donors; Journal of Armed Forces Medical college, Bangladesh. 2009; 5 (1): 4-6

12 Shrestha AC, Ghimire P, Tiwari BR, Rajkarnikar M. Transfusion-transmissible infections among blood donors in Kathmandu, Nepal. J Infect Dev Ctries 2009; 3: 794-7. 